\title{
Primary Application and Establishment of a Duplex RT-PCR Method for CyHV2 and SVCV Detection
}

\author{
Yang Zexiao, Xu Qiumei, Wang Yin, Yao Xueping, \\ Wang Kaiyu,Ren Ranyang, Li Guili,Lin Xingyu \\ College of Veterinary Medicine, \\ Sichuan Agricultural University, \\ Chengdu, China; \\ yzxyang2003@126.com
}

\author{
Li Lirui \\ Chengdu Provincial Center for Animal Disease \\ Prevention and Control \\ Chengdu, China \\ yaanwangyin@tom.com \\ 676122816@qq.com
}

\begin{abstract}
To develop the rapid method for detecting of Spring viremia of carp virus (SVCV) and Cyprinid herpesvirus 2(CyHV2), 2 pairs of specific primers for duplex ( reverse transcriptase) polymerase chain reaction (RT-PCR) were designed according to the nucleotide sequence information of CyHV2 and SVCV published in GenBank, based on the construction of recombinant plasmids pMD19-T-SVCVG and pMD19-T-CyHV2, a duplex RT-PCR method were established via a serial of tests, including reaction temperature optimization test, sensitivity and specificity tests, and primary application tests. The results showed that the detection limits of the duplex RT-PCR for CyHV2 and SVCV detection were both approximately 80 copies of the cloned viral genomic fragments, as well as resulted in no cross-reaction for GCRV, Aeromonas veronii, Pseudomonas fluorescens, and Streptococcus isolated from fish, and the DNA(cDNA) of the normal Carassius auratus gibelio samples, and the application test results showed all of the 3 CyHV2 samples proved to be CyHV2 positive and there were not any amplification for the 15 clinical samples detection by the this method. The duplex RT-PCR established here is a rapid method with high specificity and sensitivity which are suitable for CyHV2 and SVCV detection.
\end{abstract}

Key words- CyHV2; SVCV; RT-PCR; electrophoresis

\section{I . INTRODUCTION}

Viral infections remain one of the most devastating diseases in fish farming, especially the high risk and harmfulness diseases including SVC and GHFN in recent years in China, which have caused serious economic losses in the fish farming since their first outbreaks. The CyHV2 infection, caused by Cyprinid herpesvirus 2(CyHV2), is also commonly referred to as the Goldfish(Carassius auratus) Haematopoietic Necrosis (GFHN) [1,2], Since its first reported outbreak in Japan with a nearly $100 \%$ mortality rate, the CyHV2 infection has also been found with a high mortality level in many countries such as Australia, the UK, and the USA[2,3,4]. Recently, CyHV2 has also been detected in other fish species, the prussian carp $(C$. gibelio $)$ and the crucian carp (C. carassius) [5], and the CyHV-2 infection had also led to serious economic losses when it emerged in cultured gibel carp (Carassius auratus gibelio) with a severe mortality rate from 2009 to 2012 in China[6,7]. Spring viremia of carp (SVC) caused by SVCV, a rhabdovirus, is an acute hemorrhagic infectious disease with significant morbidity and mortality strongly affecting the farming of many cyprinids fish species such as common carp (Cyprinus carpio), prussian carp and so on[1,2]. Because of its significant risk and harmfulness, SVC has been registered in the list of notifiable contagious diseases to the Office International des Epizooties (OIE), and it is also designated as one of class I diseases in China[8]. while there are no very effective available vaccines that can control these diseases, and in addition Gibel carp as a major aquaculture species (Carassius auratus gibelio) has been widely cultured in nearly all of China. Therefore, it is both critical and important to study rapid detection and diagnosis techniques for preventing them. In this paper we describe and evaluate a double reverse transcription polymerase chain reaction (RT-PCR) assay for the simultaneous detection of CyHV2 and SVCV in one tube based upon our previous researches about the two diseases.

\section{II . MATERIALS AND METHODS}

\section{A.Reagents and Samples}

TIANprep Mini Plasmid Kit（DP103）, TIANgel Midi Purification Kit (DP209) , and 2×Taq PCR Master Mix were provided by TIANgen Biotech(Beijing) Co.,Ltd., RNAiso Plus, Primerscript RT reagent Kit (BK1901), and DNA Maker DL2000 were provided by the TaKaRa, Biotechnology(Dalian) Co.,Ltd. Recombinant plasmid pMD19-T-CyHV2, Grass carp reovirus(GCRV vaccine), Aeromonas veronii, Pseudomonas fluorescens, and Streptococcus isolated from fish were provided by Sichuan Agricultural University's animal quarantine lab.

\section{B. Primer Preparation.}

Using DNAStar software, 4 specific primers (listed in table 1) were carefully designed according to the sequences data of the CyHV2 DNA-dependent DNA polymerase gene[9] and SVCV glycoprotein gene published in GenBank(accession no: HM014349, EU177782)[2]. All of these primers were prepared by the TaKaRa Biotechnology Co., Ltd. 
TABLEI. PRIMERS USED FOR CYHV2 AND SVCV DETECTION

\begin{tabular}{|c|c|c|}
\hline $\begin{array}{r}\text { Primer } \\
\text { name }\end{array}$ & Sequence $\left(5^{\prime}-3^{\prime}\right)$ & $\begin{array}{l}\text { Products } \\
\text { Size(bp) }\end{array}$ \\
\hline P1c & ATAGTGTCTAGGAGCGACCCGTT & 400 \\
\hline $\mathrm{P} 2 \mathrm{c}$ & TTACAGCGTTCTCGGACCAGCAG & \\
\hline $\mathrm{P} 3 \mathrm{~s}$ & CGGATGGGCATCTGTCACAAC & 228 \\
\hline $\mathrm{P} 4 \mathrm{~s}$ & CCGTACATAATTCCTTCAACTTC & \\
\hline & GGGCATCTGTCACAACAGTGTCAA & \\
\hline $\mathrm{F} 1$ & $\begin{array}{c}\text { ATACTAATTACAAGGTAGTACCCC } \\
\text { ATTCTGTTCAT }\end{array}$ & \\
\hline & CCATTGAAGTCATGATCGATCCAG & \\
\hline R1 & $\begin{array}{c}\text { TGTCCTCCGTACGGCTCCAAATGA } \\
\text { ACAGAATGGGG }\end{array}$ & \\
\hline & ATCATGACTTCAATGGGGGCGAAT & \\
\hline $\mathrm{F} 2$ & $\begin{array}{c}\text { GCAGAGAAAAAGTGTGTGAAATG } \\
\text { AAAGGGAACCAC }\end{array}$ & \\
\hline $\mathrm{R} 2$ & $\begin{array}{c}\text { TTTCACATTCATGCTGCACGGTCTC } \\
\text { ATCTGTGATCCAAATAGAGTGGTT } \\
\text { CCCTTTCATT }\end{array}$ & \\
\hline F3 & $\begin{array}{c}\text { CAGCATGAATGTGAAAAGCACATA } \\
\text { GAGGAAGTTGAAGGAATTA }\end{array}$ & \\
\hline
\end{tabular}

C. In vitro synthesis of SVCV target DNA fragments

The conserved sequence fragment of the SVCV G gene was synthesized in vitro using an overlap extension PCR method and was then cloned into the pMD19-T vector in order to construct the recombinant plasmid named pMD19-T-SVCVG, as described in reported literature[2].

1) Overlap extension reaction.

a) the primary extension

For the primary extension procedure, a $50 \mu \mathrm{L}$ reaction volume containing $5 \mu \mathrm{L} \quad 10 \times \mathrm{Pfu}$ DNA polymerase buffer, $4 \mu \mathrm{L}$ of dNTP (10 mmol/L of each nucleotide), $1 \mu \mathrm{L}$ $(10 \mu \mathrm{mol} / \mathrm{L})$ of each of the overlapping oligo primers (F1/R1, F2/R2, or F3/R2), $1 \mu \mathrm{L}$ of Pfu DNA polymerase, and $38 \mu \mathrm{L}$ ddH $2 \mathrm{O}$ was used. The reaction conditions were $95^{\circ} \mathrm{C}$ for $30 \mathrm{~s}$ and $72^{\circ} \mathrm{C}$ for $15 \mathrm{~min}$.

b) the secondary extension

Then the secondary extension reactions were carried out until the full-length target DNA fragment production had been synthesized in the $50 \mu \mathrm{L}$ volume reaction including $1 \mu \mathrm{L} 10 \times \mathrm{Pfu}$ DNA polymerase buffer, $4 \mu \mathrm{L}$ of dNTP (10 mmol/L of each nucleotide), $1 \mu \mathrm{L}$ of Pfu DNA polymerase, and $22 \mu \mathrm{L}$ of each of the two overlap primary/previous extension reaction products. The reaction conditions were kept the same as the above-mentioned primary extension procedure. $P C R$

2)Amplification of target DNA fragments of SVCV by

From the last secondary extension reaction, the full-length target DNA fragments were amplified by PCR using the primers $\mathrm{P} 3 \mathrm{~s}$ and $\mathrm{P} 4 \mathrm{~s}$ in a $50 \mu \mathrm{L}$ reaction volume containing $25 \mu \mathrm{L} 2 \times$ Taq PCR Master Mix, $1 \mu \mathrm{L}(10 \mu \mathrm{mol} / \mathrm{L})$ of each of the primers, $3 \mu \mathrm{L}$ of template(full-length target DNA fragments), and $20 \mu \mathrm{L}$ ddH2O. The PCR was conducted as follows: denaturing at $95{ }^{\circ} \mathrm{C}$ for $5 \mathrm{~min}$; followed by 35 cycles at $95{ }^{\circ} \mathrm{C}$ for $40 \mathrm{~s}, 56{ }^{\circ} \mathrm{C}$ for $35 \mathrm{~s}$, and $72{ }^{\circ} \mathrm{C}$ for $30 \mathrm{~s}$; and then terminated by an elongation at $72{ }^{\circ} \mathrm{C}$ for $8 \mathrm{~min} .5 \mu \mathrm{L}$ of PCR products were analyzed in a $1.0 \%$ agarose in TAE Buffer gel containing $0.5 \mathrm{mg} / \mathrm{mL}$ GoldView through electrophoresis.

3) Identification of the synthesized SVCV target DNA fragments

The PCR products were subsequently separated and purified according to the TIANgel Midi Purification Kit (DP209) instructions and were then directly cloned into the pMD19-T Vector to construct the recombinant plasmids pMD19-T-SVCVG followed by a transformtion into the DH5 $\alpha$ competent cells. And the recombinant plasmids was identified by PCRs (using the special primers and RV-M/M13-47 as primers) as described in reported literature [2].

$D$.Preparation of the recombinant plasmids pMD19-TCyHV2

The recombinant plasmids pMD19-T-CyHV2 was cultured, then extracted using a TIANprep Mini Plasmid Kit and was identified by PCRs (using the special primers and RV-M/M13-47 as primers) as described in reported literature [2].

\section{E. Optimization of reaction temperature}

The optimum annealing degree for specific primers P1c, P2c, P3s and P4s was determined by a double PCR assay in one tube which used the two recombinant plasmids above as the templates in a $25 \mu \mathrm{L}$ reaction volume containing $12.5 \mu \mathrm{L} 2 \times$ Taq PCR Master Mix, $1 \mu \mathrm{L}$ $(10 \mu \mathrm{mol} / \mathrm{L})$ of each of the 4 specific primers, $1 \mu \mathrm{L}$ of each of the templates, and $6.5 \mu \mathrm{L} \mathrm{ddH}_{2} \mathrm{O}$. The reaction conditions are same as the PCR above but different from a gradient of annealing degree from $52^{\circ} \mathrm{C}$ to $60{ }^{\circ} \mathrm{C}$. In all, $5 \mu \mathrm{L}$ of PCR products were analyzed in a $1.0 \%$ agarose in TAE Buffer gel containing $0.5 \mathrm{mg} / \mathrm{mL}$ GoldView through electrophoresis.

\section{F. Specificity and Sensitivity tests}

To assess the sensitivity, the two recombinant plasmids constructed above were estimated by a ND-1000 ultraviolet spectrophotometer (Nano Drop Co.,Ltd,USA) and were then amplified in a 10-fold serial dilution[9]by duplex RT-PCR using the optimum reaction system and conditions as determined above. The specificity of the duplex RT-PCR with the 4 specific primers was assessed through comparing the recombinant plasmids to GCRV, Aeromonas veronii, Pseudomonas fluorescens, and Streptococcus isolated from fish and to a negative tissue sample of Gibel carp. The RNA extraction of GCRV and tissue sample using the method in reference SN/T 1152-2002 , and RT reaction using Primerscript RT reagent Kit. The samples DNA templates were prepared by using TIANgel Midi Purification Kit(DP09-02).

\section{G. Primary application test}

To evaluate the reliability of the duplex RT-PCR, 3 positive gibel carp samples infected with CyHV2 collected in 2012 and 15 normal clinical samples collected from markets were detected by duplex RT-PCR using the optimum reaction system and conditions.

\section{III.RESULT}

\section{A. Synthesis of templates DNA fragments of SVCV}

A conserved sequence fragment of the SVCV G gene about 228 bp was synthesized in vitro using an overlap 
extension PCR method (see Fig .1 lane2), and was cloned into the pMD9-T vector to construct the recombinant plasmid named pMD19-T-SVCVG. Then the recombinant plasmid pMD19-T-SVCVG were identified by two types of PCR methods as described above, the results (see Fig .2)showed the PCR products of the pMD19-T-SVCVG from the pMD19-T vector usual primers(lane2) were longer than the PCR products from the special primers ( $\mathrm{P} 3 \mathrm{~s} / \mathrm{P} 4 \mathrm{~s})$ (lane1), which were 228bp. The results is indicative that pMD19-T-SVCVG was constructed successfully.

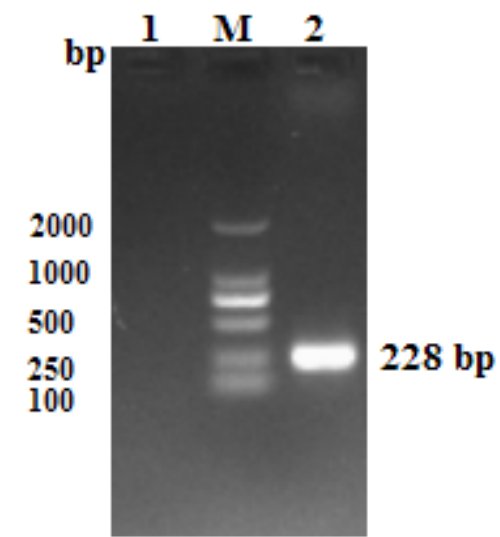

Figure1. The Synthesis results of SVCV G gene by overlapping PCR M: DNA marker DL2000;

1:Negtaive control,2: target DNA fragments of SVCV

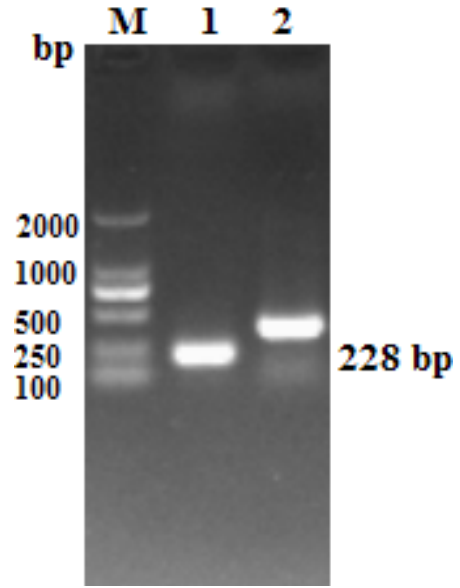

Figure2. The PCRs identification results of the pMD19-T-SVCVG M: DNA marker DL2000

1: $\mathrm{PCR}(\mathrm{P} 3 \mathrm{c} / \mathrm{P} 4 \mathrm{c}$ as primer) products of $\mathrm{PMD} 19-\mathrm{T}-\mathrm{SVCVG}$,

2: PCR(RV-M/M13-47 as primers) products of pMD19-T- SVCVG

\section{B. Identification of templates DNA fragments of CyHV2}

To develop a duplex RT-PCR for SVCV and CyHV2 detection, the constructed recombinant plasmid pMD19-T-CyHV2 was both prepared and identified by two types of PCR methods as described above, the results(see Fig .3)showed the PCR products of the pMD19-T-CyHV2 from the pMD19-T vector usual primers(lane2) were longer than the PCR products from the special primers $\mathrm{P} 1 \mathrm{c} / \mathrm{P} 2 \mathrm{c}$ (lane1), which was about 400 bp. these results are indicative that the templates DNA fragments were prepared successfully.

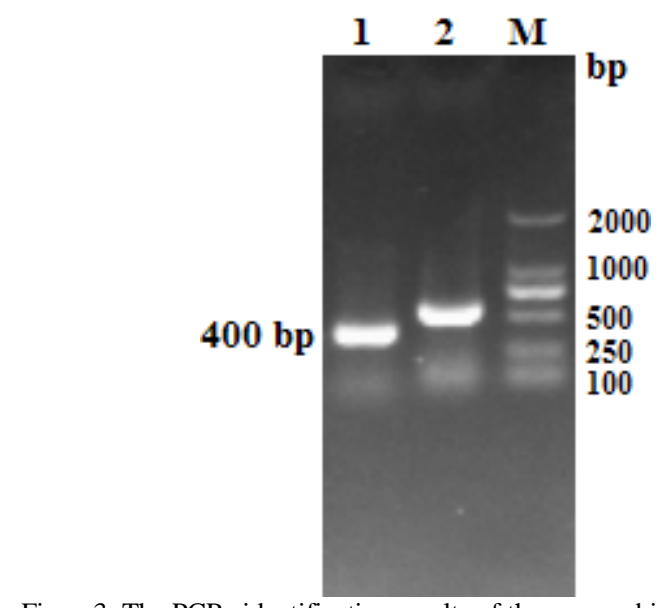

Figure3. The PCRs identification results of the recombinant plasmid of pMD19-T-CyHV2.

M: DNA marker DL2000;

1: $\mathrm{PCR}(\mathrm{P} 1 \mathrm{c} / \mathrm{P} 2 \mathrm{c}$ as primer) products of $\mathrm{pMD} 19-\mathrm{T}-\mathrm{CyHV} 2$,

2: PCR(RV-M/M13-47 as primers) products of pMD19-T-CyHV2

\section{Optimization of reaction conditions.}

The two recombinant plasmids were used in the gradient duplex PCR to determine an ideal annealing degree. The results show that the PCR products of SVCV and CyHV2 in lane6 $\left(59^{\circ} \mathrm{C}\right)$ are both present in a greater quantity than in the other lanes (see Fig .3), which indicates that $59^{\circ} \mathrm{C}$ is the ideal annealing degree in the amplification cycles for creating a high specificity and amplification efficiency.

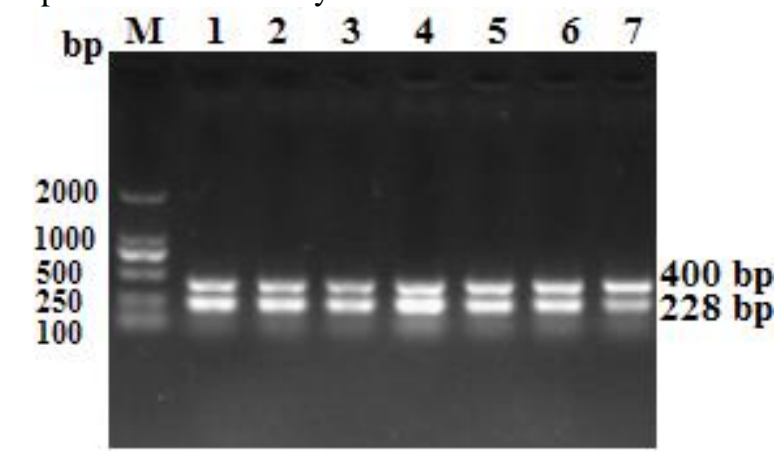

Figure 4.The optimization results of annealing degree determination M: DNA marker DL2000,1:52 ${ }^{\circ} \mathrm{C}, 2: 53^{\circ} \mathrm{C}, 3: 55^{\circ} \mathrm{C}, 4: 57^{\circ} \mathrm{C}, 5: 58^{\circ} \mathrm{C}$, $6: 59^{\circ} \mathrm{C}, 7: 60^{\circ} \mathrm{C}$

\section{D.Specificity and sensitivity of duplex RT-PCR}

The sensitivity and specificity of the duplex RT-PCR were assessed in the tests that were previously described above. There were two clear electrophoretic bands located at about $400 \mathrm{bp}$ and $228 \mathrm{bp}$ separately for CyHV2 and SVCV detection could be both observed (Fig .4 lane 4) when almost 80 copies of the target DNA fragments in each of the 2 recombinant plasmids were detected(see Fig .4).For the specificity(see Fig .5), the two expected PCR products that were only observed for the recombinant plasmids detection (Fig .5 lane1,lane3 and lane4), and no specific amplification products were observed for the detection of GCRV, Aeromonas veronii, Pseudomonas fluorescens, and Streptococcus isolated from fish, and the DNA(cDNA) of the normal Carassius auratus gibelio samples. 

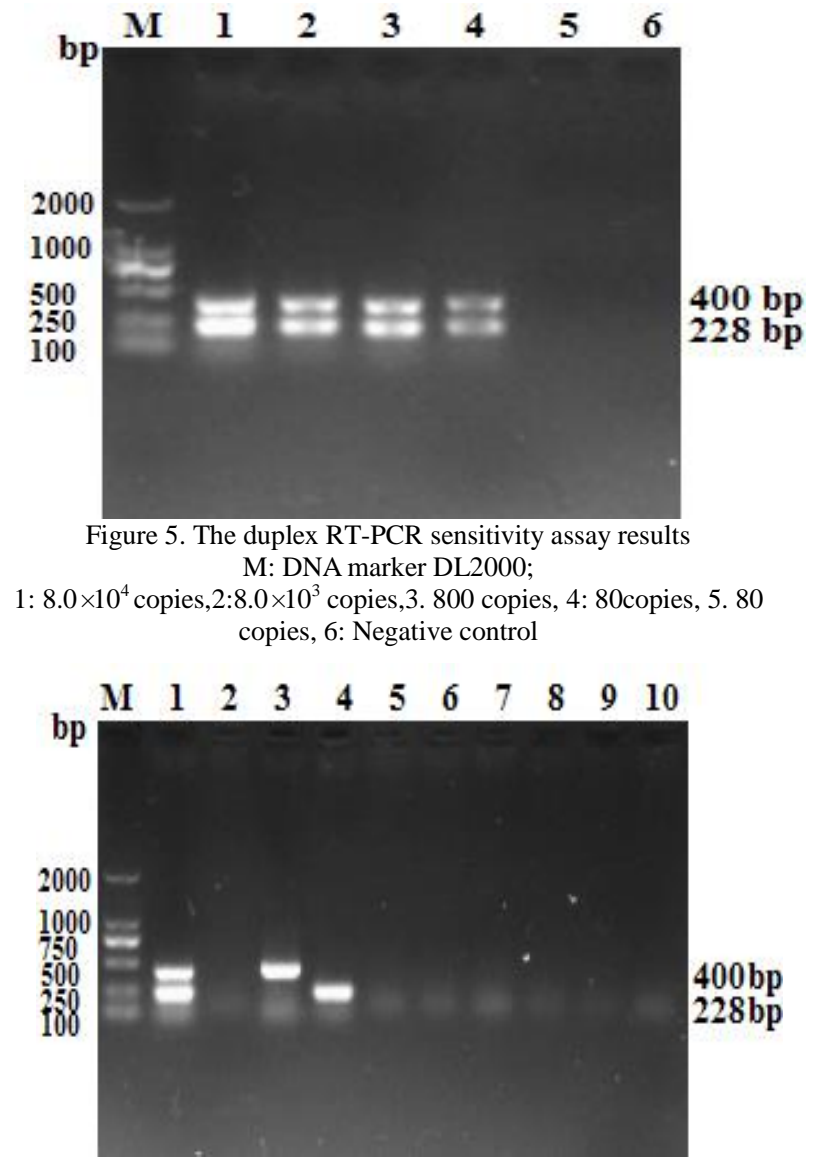

Figure 6 . The duplex RT-PCR specificity assay results M: DNA marker DL2000, 1:Positive control, 2:Negative control, 3:pMD19-T-CyHV2, 4: pMD19-T-SVCVG, 5:GCRV, 6:Aeromonas veronii, 7: Pseudomonas fluorescens,8: Streptococcus, 9: Tissues DNA of healthy Carassius auratus gibelio, 10: Tissues RNA of healthy Carassius auratus gibelio.

E.Primary application of CyHV2-SVCV duplex $R T-P C R$

18 gibel carp clinical samples were detected by using the duplex RT-PCR. The results（see Fig .6) showed that all of the 3 CyHV2 infection samples(collected in 2012) proved to be CyHV2 positive (lane6, lane7 and lane8), the detection positive rate of CyHV2 infection was $100 \%$, and there were not any amplification for the other clinical samples detection.



Figure 7The application assay results of some clinical samples M: DNA marker DL2000; 1,2,3,4 and 5 means normal gibel carp clinical samples, respectively; 6,7 and 8 means the CyHV2 infection gibel carp clinical samples; 9: Negative control, 10: Positive control.

\section{IV.DISCUSSION AND CONCLUSIONS}

SVCV and CyHV2 has been the important pathogens which negatively impact of the ecology and environment of warm-water fish farming throughout the world and become the significant diseases to prevent and control in gibel carp farming now. As there is no ideal vaccine, developing a rapid detection and diagnosis technology has important significance for SVCV and CyHV2 control with the development of international trade. Currently, several available methods have been reported to detect SVCV or CyHV2 including ELISA, (RT-)PCR, real-time PCR and (RT-) LAMP[2,10,11], but there is seldom reports on the duplex PCR method for SVCV and CyHV2 detection in one tube simultaneously. In this paper, two pairs of specific duplex PCR primers for SVCV and CyHV2 detection were designed and evaluated after set of serial tests. This is the first report on the application and development of SVCV and CyHV2 duplex RT-PCR method in Gibel carp in China.

In conclusion, the duplex RT-PCR have been proven to be a high sensitive and specific method for CyHV2 and SVCV rapidly detecting in Gibel carp primary. The detection limits of this method described here could reach as few as about 80 copies of the each virus target gene fragments, and no cross reaction was observed with other common main pathogens, including GCRV, Aeromonas veronii, Pseudomonas fluorescens, and Streptococcus isolated from fish and the normal Carassius auratus gibelio sample as detected by this method. In brief, this study supplied a new, simple, rapid, and useful detection and diagnostic tool for the molecular epidemiology investigation of CyHV2 and SVCV in China.

\section{ACKNOWLEDGEMENT}

This study was supported by Grants from Sichuan provincial department of science and technology project (2014NZ0003), the planning subject of 'the twelfth five-year-plan' in national science and technology for the rural development in China(2013BAD12B04), and "211-Projects" Shuangzhi Plan in Sichuan Agricultural University. Xu qiumei, Yao Xueping, Wang Yin, Li Lirui and Wang Kaiyu should be also considered as the same first authors.

\section{REFERENCES}

[1] K.Xiao and C.Chen. Microbiology in aquaculture,the 1st ed, Beijing:Chinese agriculture Press,Dec,2004,pp.256-257

[2] Z.Yang, Q.Xu, L. Li, Y.Wang, X.Yao, K.Wang, R.Ren, H.Ya, S. Peng, G.Li and X.Lin, "Designment and Evaluation of the Primers for Cyprinid Herpesvirus 2 and Spring Viremia of Carp Virus Duplex RT-PCR Detection", Biotech.: Indian J., vol.10, Dec. 2014, pp. 12390-12395.

[3] K.R.Jeffrey, K.Bateman, A. Bayley, S.W.Feist, J.Hulland, C.Longshaw, D.Stone, G.Woolford and K. Way, "Isolation of a Cyprinid herpesvirus 2 from goldfish,Carassius auratus (L), in the UK”. J. Fish Dis., vol.30, 2007, pp. 649-656

[4] J He, X Shi, L Yu, X Zheng, W Lan, P Jia, J Wang and H Liu. "Development and evaluation of a loop-mediated isothermal amplification assay for diagnosis of Cyprinid herpesvirus 2". J Virol Methods., vol.194, Feb.2013,pp. 206-210

[5] G Fichi, G Cardeti, C Cocumelli, N Vendramin, A Toffan, C Eleni, N Siemoni, R Fischetti, and F Susini. "Detection of Cyprinid herpesvirus 2 in association with an Aeromonas sobria infection of 
Carassius carassius (L.), in Italy”. J Fish Dis., vol.36, Oct.2013, pp. 823-830

[6] L.Wang , J. He, L.Liang , X.Zheng, P.Jia , X. Shi,, W.Lan , J.Xie H.Liu and P.Xu, "Mass mortality caused by Cyprinid herpesvirus 2 (CyHV-2) in Prussian carp (Carassius gibelio) in China". Bull. Eur. Assoc. Fish Pathol. , vol.32, 2012, pp. 164-173

[7] J Xu, L Zeng, H Zhang, Y Zhou, J Ma and Y Fan. "Cyprinid herpesvirus 2 infection emerged in cultured gibel carp, Carassius auratus gibelio in China". Vet Microbiol., vol. 166, Jan.2013, pp. $138-144$

[8] N. Z.Zhang, L. F.Zhang, Y.N.Jiang, T.Zhang and C. Xia "Molecular Analysis of Spring Viraemia of Carp Virus in China: A Fatal Aquatic Viral Disease that Might Spread in East Asian." PLoS One., vol.
4,July 2009, e6337

[9] Z.Yang, G. Li, Q.Xu, Y.Wang, X.Yao, L.Zhu, Z.Xu, D.Chen, K.Wang ,(2014) "A PCR Method for the Detection of Cyprinid Herpesvirus 2”,J. Pur. Appl. Microb., vol.8, May. 2014, pp. 605-610 [10] H Zhang, L Zeng, Y Fan, Y Zhou, J Xu and J Ma. “ A

Loop-Mediated Isothermal Amplification Assay for Rapid Detection of Cyprinid Herpesvirus 2 in Gibel Carp (Carassius auratus gibelio)", ScientificWorldJournal., Jan 2014, Published online.

[11] RB Shivappa, R Savan, T Kono, M Sakai, E Emmenegger, G Kurath and JF Levine. "Detection of spring viraemia of carp virus (SVCV) by loop-mediated isothermal amplification (LAMP) in koi carp, Cyprinus carpio L.” J Fish Dis., vol.31, April. 2008, pp. 249-258 